\title{
Pengaruh Profesionalisme, Etika Auditor, Pengalaman Kerja, dan Fee Audit terhadap Kualitas Audit pada KAP Medan
}

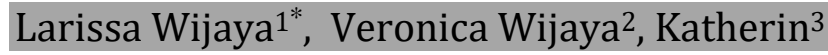 \\ 1,2,3Universitas Prima Indonesia, Medan - Indonesia
}

\author{
A R T I C L E I N F O \\ Article history: \\ Received October, 132021 \\ Received in revised form \\ November, 122021 \\ Accepted November, 15 \\ 2021 \\ Available online December, \\ 252021 \\ Kata Kunci: \\ Etika auditor \\ professionalism, \\ pengalaman kerja, fee \\ audit, kualitas audit. \\ Keywords: \\ Auditor ethics, \\ professionalism, work \\ experience, auditfee, quality \\ audit.
}

\begin{abstract}
A B S T R A K
Dalam proses perolehan kualitas sebuah laporan keuangan, para-auditor sangat diperlukan untuk menguasai dasar yang bagus. Pengkajian ini menyertakan responden yang berada dikota Medan. Dikarenakan kota Medan memiliki jumlah KAP dalam skala yang relatif luas dan memiliki tuntutan agar keberadaan auditor untuk independen melaksanakan pengkajian terhadap laporan keuangan dalam mengajukan pandangan atas dasar riset tersebut, maka peran serta dalam penentuan kualitas audit cukup representatif agar dilaksanakannya penelitian ini. Profesionalisme, etika auditor, pengalaman kerja, dan fee audit semuanya memberi dampak kualitas audit pada kantor KAP Medan. Penelitian ini bersifat kuantitatif dan teknik pengumpulan data dengan membagikan kuesioner. Kantor Akuntan Publik Medan adalah fokus demografi penelitian. Didalam riset berikut jumlah auditor yaitu sebanyak 92 orang. Data tersebut diuji dengan mempergunakan statistik deskriptif, kemudian uji asumsi klasik menggunakan uji normalitas, multikolinearitas, heteroskedastisitas dan glesjer serta uji hipotesis menggunakan model regresi berganda yang dibantu oleh software IBM SPSS Statistics 22. Profesionalisme, etika auditor pengalaman kerja, dan fee audit memaparkan 17,5\% kualitas audit, dan $82,5 \%$ ialah variable yang tidak diuraikan dalam penelitian ini.
\end{abstract}

\section{A B S T R A C T}

In the process of obtaining the quality of a financial report, auditors are needed to master a good basis. This study includes respondents who are in the city of Medan. Due to the fact that the city of Medan has a number of KAPs on a relatively wide scale and demands that the presence of auditors be independent to carry out a review of the financial statements in presenting their views on the basis of the research, the participation in determining audit quality is representative enough for this research to be carried out. Professionalism, auditor ethics, work experience, and audit fees all have an impact on audit quality at the Medan KAP office. This research is quantitative and the data collection technique is by distributing questionnaires. The Medan Public Accounting Firm is the focus of the research demographics. In the following research, the number of auditors is 92 people. The data was tested using descriptive statistics, then tested the classical assumptions using normality, multicollinearity, heteroscedasticity and glesjer tests and hypothesis testing using multiple regression models assisted by IBM SPSS Statistics 22 software. Professionalism, work experience auditor ethics, and audit fees explain $17.5 \%$ of audit quality, and $82.5 \%$ are variables not described in this study.

\footnotetext{
* Corresponding author.

E-mail : lissahuang55@gmail.com (Larissa Wijaya)
} 


\section{Pendahuluan}

Didalam beberapa tahun terakhir, adanya profesi auditor telah menjadi isu publik dikarenakan pada era globalisasi telah dilaksanakan kegiatan audit. Adanya kerjasama antara auditor dengan manajemen bisnis ataupun klien guna dalam memudahkan mengumpulkan bukti, seperti data kepemilikan maupun laporan audit, dimana adanya verifikasi laporan ini menjamin keakuratan akun keuangan serta kepuasan komitmen keuangan. Auditor mampu menghasilkan audit report yang cukup berkualitas dalam mempergunakan standart IAPI. Sehingga kualitas audit termasuk membenarkank laporan keuangan klien.

Norma etika dapat memberi dampak terhadap professional, sehingga dapat menghasilkan kegagalan seorang auditor terkait dengan masalah perusahaan. Hal ini mampu melemahkan kepercayaan publik ataupun perusahaan terhadap auditor, khususnya bagi pengguna laporan keuangan, serta cukup membahayakan integritas mereka. Beberapa kasus yang telah ditangani oleh kementerian keuangan mempertunjukkan adanya kelemahan kode etik profesi audit di Indonesia (Kemenkeu). Tahun buku 2018 tercermin pada garuda Indonesia (2019) serta PT. Hanson (2016). Garuda Indonesia Group mencatat net income sebanyak USD809,85 ribu ataupun Rp11,33 miliar. Dengan defisit tahun 2017 cukup signifikan, yakni sebanyak USD216,5 juta. PSAK tidak mengakui pembukuan keuangan GARUDA INDIA 2018. Dalam studi kasus EY PT Hanson International Tbk (2016), Kami menemukan Sherly melanggar SPAP SA 200 dan IIPM 130. PT. Hanson International Tbk ditemukan melanggar KAP pada tahun 2016 dikarenakan kelalaian didalam meninjau catatan keuangan.

Adapun aspek lain yang merupakan dampak atas kualitas audit ialah fee audit. Kualitas auditor memberi dampak atas fee audit sebagaimana laporan keuangan juga bisa mendorong auditor guna meningkatkan kinerjanya.

Sebagai seorang auditor sangat diperlukannya professional mentality, bakat, ataupun keterampilan yang memadai, serta sikap disiplin dan gigih (Futri \& Juliarsa, 2014). Profesionalisme memiliki beberapa indikator yakni, (1) Pengabdian pada profesi, profesionalisme bisa dipertunjukkan melalui pemanfaatan informasi serta kemampuan yang telah diperoleh; (2) Kewajiban sosial, nilai profesi memberi keuntungan bagi masyarakat serta professional dipandang sebagai kewajiban sosial; (3) Kemandirian, dampak eksternal dianggap sebagai penghalang bagi otonomi professional; (4) Keyakinan akan profesi, gagasan bahwasanya hakim terbaik dari kinerja professional ialah professional lain, bukan nonahli; (5) hubungan dengan rekan seprofesi, koneksi profesional, baik kelompok rekan kerja resmi maupun informal, ialah konsep utama didalam pekerjaan (Kusuma, 2012)

Etika auditor wajib ditegakkan agar meningkatkan kualitas audit (Kurnia et al., 2014). Adapun indikator sebagai berikut, (1) Integritas, auditor yang jujur, adil, serta tulus didalam praktiknya; (2) objektivitas, auditor wajib bersikap objektif dalam melaksanakan tugas audit, menginterpretasikan bukti audit serta mereview seluruh laporan keuangan; (3) Kompetensi professional serta kecermatan, agar dapat memberikan jasanya, seorang auditor wajib berpengetahuan serta terampil didalam profesinya; (4) Kerahasiaan, kecuali diwajibkan oleh hukum, auditor wajib menjaga kerahasiaan atas informasi kliennya; (5) Periilaku professional, ketidakmampuan didalam menjalankan tugas, melecehkan pihak lain, serta membandingkan baik serta buruk ialah perilaku yang dilarang bagi auditor (Kasbudiyani \& Mahsun, 2017)

Auditor yang berpengalaman dapat berkinerja lebih baik dibandingkan dengan auditor pemula (Tandiontong, 2013). Pengalaman kerja dapat dinilai dari, (1) Pengalaman audit, kualitas atas hasil pemeriksaan tergantung pada pengalaman, objektivitas, serta kompetensi auditor; (2) Tugas audit, semakin banyaknya tugas yang telah dilakukan oleh auditor, maka auditor akan memperoleh kemampuan yang lebik baik dalam menemukan hal-hal yang perlu melakukan perawatan tertentu ataupun perawatan dimana sering dia lihat dan memiliki karakteristik yang bervariasi; (3) Perusahaan yang diaudit, semakin banyak perusahaan yang diaudit oleh auditor, maka pengalaman yang diterima oleh auditor akan semakin bertambah (Ismiyati, 2012)

Fee auditor ialah imbalan klien ataupun pihak lain atas keterlibatannya (Agoes, 2012). Pemberian ataupun penerimaan komisi mengurangi independensi anggota KAP (SPAP 240.1, 2011), kontrak jasa professional. Pelaksana dapat menetapkan biaya layanan profesipnal. Fee audit dapat dikaitkan dengan, (1) Risiko penugasan, fee audit sering dikaitkan dengan risiko bawaan dan risiko informasi; (2) Kompleksitas jasa yang diberikan, kesulitan yang dihadapi oleh auditor disaat melaksanakan audit, harga audit meningkat dengan kompleksitas, pelanggan dan ruang lingkup layanan; (3) Struktur biaya KAP, pertimbangan professional audit serta biaya yang terkait dengannya ditentukan oleh kualitas bukti yang dikumpulkan; (4) Ukuran KAP, reputasi kantor akuntan publik akan dimasukkan kedalam fee audit (Agoes, 2012). 
(Tandiontong, 2016) kualitas audit memungkinkan seorang auditor mendeteksi maupun mengungkapkan adanya kelemahan didalam sistim akuntansi kliennya. Akuntan publik mampu menghubungkan kepentingan investor serta kreditur dengan manajemen Didalam mengelolah keuangan usaha. Dalam skenario terbuka, akuntan wajib bertindak jujur, intelektual, dan professional mengenai KAP, (Primadi, 2018) 4 faktor yang diteliti berkaitan dengan kualitas audit, (1) Lama waktu auditor, masa waktu auditor mengaudiit pelanggan berdampak pada kulitas audit; (2) Jumlah klien, basis pelanggan yang besar berarti auditor akan bekerja keras dalam menjaga repurtasi mereka; (3) Kesehatan keuangan klien, jika situasi keuangan pelanggan baik, klien dapat mendorong auditor agar menyimpang.; (4) Review pihak ketiga, meminta tinjauan pihak ketiga atas temuan audit dapat meningkatkan kaulitas audit.

Sesuai dengan uraian periset, riset ini berusaha agar mengevaluasi dampak yang dihasilkan oleh profesionalisme, etika, pengalaman, serta fee terhadap kualitas audit yang sesuai dengan ekspetasi masyarakat pada umumnya. Pengkajuan ini menyertakan responden yang telah berlangsung pada kota medan, dikarenakan kota medan telah memiliki jumlah KAP dalam skala yang cukup luas maupun kecil yang menurut keberadaan auditor independen dalam melaksanakan pengkajian terhadap laporan keuangan dalam mengajukann pandangan atas dasar riset tersebut, sehingga peran serta didalam penentuan kualitas audit serta cukup representative untuk dilaksanakannya penelitian ini.

\section{Metode}

Lokasi riset dilaksanakan di Kantor Akuntan Publik Medan. Riset ini menggunakan pendekatan dengan angka sebagai data yang disebut kuantitatif. Sifat penelitian ini adalah perbandingan kausalitas. Artinya, melihat kemungkinan hubungan sebab akibat berdasarkan pengamatan terhadap efek yang ada dan mencari faktor penyebab potensial melalui data tertentu. Sampel terdiri dari 92 auditor Kantor Akuntan Publik Medan dengan membagikan kuesioner secara langsung kepada auditor di 7 tempat yang berbeda. Karena populasi dibawah 100 peserta, sample jenuh dipergunakan. Temuan ini berlandaskan data dari Kantor Akuntan Publik Medan. Data dilaporkan mempergunakan statistik deskriptif. Metode pengukuran sentiment mempergunakan skala Likert.

Uji asu,msi klasik terdiri atas uji normallitas, bertujuan agar mengevaluasi apakah variable pengganggu ataupun residual didalam model regresi memiliki normal distribution; uji multikolinearitas, bertujuan agar melihat apakah variable independent didalam model regresi berkorelasi; uji heterokedastisitas, ber tujuan memeriksa apakah residual model regresi berbeda diseluruh pengamatan dan uji glesjer bertujuan menilai apakah temuan probabilitas significant jikalau nilai significantsi $>5 \%$. Pengujian ini mempergunakan software IBM SPSS Statistics 22.

Uji hipotesis dengan uji R2 mengevaluasi kapasitas varian dari variabel independen dapat memaparkan variable dependen. Nilai R2 kecil berarti variabel independen sangat terbatas untuk menjelaskan variabel dependen. Nilai yang mendekati 1 bebas menyediakan hampir semua informasi yang dibutuhkan untuk memprediksi variasi variabel terikat. Untuk setiap atau lebih variabel bebas, R2 harus ditingkatkan terlepas dari apakah variabel memiliki pengaruh yang signifikan terhadap variabel terikat; uji statistic F dipergunakan agar mengkonfirmasi variabel independen juga memperngaruhi variabel dependen (95\% confidence $(\alpha=5 \%)$ ), kriteria pengambilan keputusan adalah dengan membandingkan variable thitung : H0 akan diterima jikalau Fhitung $\leq$ Ftabel kepada $\alpha=5 \%$, dan sebaliknya bila Fhitung > Ftabel kepada $\alpha=5 \%$ maka Ha diterima dan pengujian statistics $t$ dipergunakan agar melihat variabel independen beri dampak variable dependen, kriteria keputusan yang dipergunakan agar membandingkan ialah: $\mathrm{HO}$ akan diterima jikalau -ttabel $\leq$-thitung kepada $\alpha=5 \%$ dan sebaliknya -thitung $\leq$-ttabel kepada $\alpha=5 \%$ maka Ha diterima.

\section{Hasil dan pembahasan}

Uji Validitas bertujuan memperkirakan apakah suatu kuesioner valid ataupun tidak valid, Dengan nilai probabilitas korelasi sebesar 0,000 maka estimasi hasil pengujian Professionalisme, Etika Auditor, Pengalaman Kerja, Fee audit dan Kualitas Audit ialah $>0,36$. Dari hasil pengujian mengunakan SPSS, setiap butir pertanyaan dalam variable yang ditentukan memiliki nilai diatas 0,36 . Hasilnya, semua temuan ialah valid. Kemudian, Uji Reliabilitas untuk mengukur consistent variable pada objek yang sama, Dengan nilai Cronbach's alpha > 0,60 agar setiap varibel reliabel. Semua variable memiliki hasil pengujian diatas 0,60. Faktor Professionalisme, Etika Auditor dan Pengalaman Kerja mempertunjukkan Reliabel maka semua item bisa diterima untuk diteliti. 
Tabel 1. Hasil Analisis Regresi Berganda terhadap Kualitas Audit

\begin{tabular}{lccccc}
\hline & \multicolumn{2}{c}{$\begin{array}{c}\text { Unstandardized } \\
\text { Coefficients }\end{array}$} & $\begin{array}{c}\text { Standardized } \\
\text { Coefficients }\end{array}$ & & \\
\cline { 2 - 4 } \multicolumn{1}{c}{ Model } & $\mathrm{B}$ & Std. Error & Beta & $\mathrm{T}$ & Sig. \\
\hline 1 (Constant) & 36.725 & 13.091 & & 2.805 & .007 \\
Profesionalisme & .180 & .203 & .104 & .889 & .377 \\
Etika Auditor & -.328 & .139 & -.284 & -2.370 & .021 \\
Pengalaman Kerja & -.195 & .127 & -.184 & -1.542 & .129 \\
Fee Audit & .462 & .127 & .441 & 3.639 & .001 \\
\hline
\end{tabular}

Hasil persamaan regresi berganda diturunkan dari table diatas serta dinyatakan :

Kualitas Audit $=36,725+0,180$ Professionalism $+-0,328$ EtikaAuditor +-

0,195PengalamanKerja + 0,462FeeAudit

Persamaan yang ada diatas dapat diuraikan :

1. Nilai constant $(\alpha)$ sebanyak 36,725 artinya jikalau tidak terdapat variable Professionalisme, Etika Auditor, Pengalamann Kerja, dan Fee Audit konstan, maka Kualitas Audit ialah 36,725.

2. Professionalism (X1) 0,180 artinya setiap kenaikan variabel Professionalisme sebanyak satu, maka nilai Kualitas Audit naik sebesar 0,180 dengan premis variable bebas lainnya tetap.

3. Etika Auditor (X2) $-0,328$ artinya setiap penurunan variable etika auditor sebanyak satu, maka nilai Kualitas Audit turun sebesar $-0,328$ dengan premis variable bebas lainnya tetap.

4. Pengalaman Kerja (X3) $-0,195$ artinya setiap penurunan variable Pengalaman Kerja sebanyak satu, maka nilai Kualitas Audit turun sebesar -0,195 premis asumsi variable bebas lainnya tetap.

5. Fee Audit (X4) 0,462 artinya setiap kenaikkan variable Fee Audit sebanyak satu, maka nilai Kualitas Audit naik sebesar 0,462 dengan premis variable bebas lainnya tetap.

Tabel 2. Hasil Uji R² Pengaruh Profesionalisme, Etika Auditor, Pengalaman Kerja, Fee Audit terhadap Kualitas Audit

\begin{tabular}{|c|c|c|c|c|}
\hline \multicolumn{5}{|c|}{ Model Summary } \\
\hline Model & $\mathrm{R}$ & R Square & $\begin{array}{l}\text { Adjusted R } \\
\text { Square }\end{array}$ & $\begin{array}{c}\text { Std. Error of the } \\
\text { Estimate }\end{array}$ \\
\hline 1 &, $479^{a}$ & ,229, & , 175 & 2,200 \\
\hline
\end{tabular}

Adjusted R Square ialah 0,175. Kualitas audit KAP Medan dipaparkan 17,5\% oleh professionalisme, etika auditor, pengalaman kerja, dan fee audit. Faktor lain yang tidak termasuk Didalam riset ini, seperti jenis kelamin ataupun masa kerja, beri dampak kualitas audit. $82.5 \%$ ialah variable lain yang tak dijelaskan dalam penelitianini.

Tabel 3. Hasil Uji F Pengaruh Profesionalisme, Etika Auditor, Pengalaman Kerja, Fee Audit terhadap Kualitas Audit

\begin{tabular}{rlrrrrr}
\hline \multicolumn{7}{c}{ ANOVA $^{\text {a }}$} \\
\hline Model & Sum of Squares & df & Mean Square & F & \multicolumn{1}{c}{ Sig. } \\
1 & Regression & 82,062 & 4 & 20,516 & 4,239 &, $005^{\text {b }}$ \\
Residual & 275,873 & 57 & 4,840 & & \\
Total & 357,935 & 61 & & & \\
\hline
\end{tabular}

a. Dependent Variable: $Y$

b. Predictors: (Constant), X4, X1, X3, X2 
Fhitung Didalam riset berikut ialah 4,239 dengan taraf keyakinan 95 persen $=5 \%$, df1 (jumlah variable-1)=3 serta df2 $(\mathrm{n}-\mathrm{k})=62$, sehingga Ftabelnya ialah 2,76, sesuai Tabel 3. Fhitung > Ftabel $(4,239>2,76)$ terbukti demikian, dengan nilai signiificant 0,005 0,05 maka Ha di terima dan H0 di tolak.

Tabel 4. Uji t Pengaruh Professionalisme, Etika Auditor, Pengalaman Kerja, Fee Audit terhadap Kualitas Audit

\begin{tabular}{|c|c|c|c|c|c|c|c|c|}
\hline & \multirow[b]{2}{*}{ Model } & \multicolumn{2}{|c|}{$\begin{array}{l}\text { Unstandardized } \\
\text { Coefficients }\end{array}$} & \multirow{2}{*}{$\begin{array}{c}\text { Standardized } \\
\text { Coefficients }\end{array}$} & \multirow[b]{2}{*}{$\mathrm{T}$} & \multirow[b]{2}{*}{ Sig. } & \multicolumn{2}{|c|}{$\begin{array}{l}\text { Collinearity } \\
\text { Statistics }\end{array}$} \\
\hline & & B & Std. Error & & & & Tolerance & VIF \\
\hline \multirow[t]{5}{*}{1} & (Constant) & 36.725 & 13.091 & & 2.805 & .007 & & \\
\hline & Profesionalisme & .180 & .203 & .104 & .889 & .377 & .989 & 1.011 \\
\hline & Etika Auditor & -.328 & .139 & -.284 & -2.370 & .021 & .944 & 1.059 \\
\hline & Pengalaman Kerja & -.195 & .127 & -.184 & -1.542 & .129 & .949 & 1.054 \\
\hline & Fee Audit & .462 & .127 & .441 & 3.639 & .001 & .921 & 1.086 \\
\hline
\end{tabular}

Penjelasan hasil penelitian dapat dipaparkan dengan mempergunakan Tabel 4 diatas: $\mathrm{n}-\mathrm{k}-1=62-$ $4-1=57 ; \mathrm{df}=0,050$; Nilai ttabel $=2,00172$ Variable Professionalism memiliki significance value sebanyak 0,377 $>0,05$ sebagaimana terlihat pada tabel Berlandaskan uji SPSS. t-tabel $(0,889<2,002)$ hasil t-hitung ialah HO diterima dan Ha ditolak. Variable Etika Auditor memiliki significance value sebanyak 0,377 $>0,05$ sebagaimana terlihat pada tabel Berlandaskan uji SPSS. $(-2.370>-2.002)$ ialah hasil dari -thitung $>-$ ttabel ialah H0 ditolak dan Ha diterima. Variabel Pengalaman Kerja memiliki significance value sebanyak $0,377>0,05$ bersumber dari uji SPSS. -thitung -ttabel $(-1,542<-2,002)$ ialah H0 diterima dan Ha ditolak. Variable Audit Fee memiliki significance value sebanyak 0,377 $>0,05$, seperti terlihat pada tabel. thitung $>$ ttabel $(3,639>2)$ hasilnya ialah H0 ditolak dan Ha diterima.

\section{Pengaruh Professionalisme terhadap kuallitas audit}

Professionalisme memiliki significance value sebanyak 0,377 $>0,05$ dan thitung $<$ ttabel $(0,889<$ 2,002), maka H0 disetujui sedangkan Ha ditolak. Penelitian tidak didukung (Agusti \& Pertiwi, 2013) yang menemukan bukti bahwasannya professionalisme meningkatkan kualitas audit. Namun penelitian didukung (Futri \& Juliarsa, 2014) Demikian kami simpulkan penentu professional atau tidaknya auditor tak ditentukan dalam menghasilkan kualitas audit, tak hanya dinilai dari laporan keuangan yang dihasilkan, juga kedekatan rekan professional, dan dedikasi terhadap pekerjaan mereka untuk peroleh indikator audit berkualitas tinggi. Maka Professionalisme berdampak kecil pada kualitas audit.

\section{Pengaruh Etika Auditor terhadap Kualitas Audit}

Etika Auditor memiliki significance value sebanyak 0,377 $>0,05$ dan thitung $<$ ttabel $(-2,370>-$ 2,002), dengan demikian Ha diterima dan HO ditolak dan memiliki pengaruh negatif. Hasil penelitian ini bertentangan dengan (Futri \& Juliarsa, 2014) yang menyatakan bahwasannya etika auditor meningkatkan kualitas audit, berbeda dengan (Savitri \& Astika, 2017) yang mendukung penelitian ini. Demikian kami simpulkan meskipun semakin tinggi etika seorang auditor tidak dapat menjadi tolak ukur dalam menentukan hasil dari kualitas yang diauditnya, etika auditor adalah sikap dan perilaku dalam mentaati peraturan, kewajiban dan norma-norma dalam kehidupan, tidak dapat menentukan cermat atau telitinya seseorang dalam mengaudit laporan keuangan. Maka Etika Auditor berdampak negatif pada kualitas audit.

\section{Pengaruh Pengalaman Kerja terhadap Kualitas Audit}

Professionalisme memiliki significance value $0,377>0,05$ dan thitung ttabel $(-1.542<-2.002)$, dengan demikian $\mathrm{HO}$ diterima dan Ha ditolak. Pengalaman kerja meningkatkan kualitas audit, bersumber dari (Hanjani, 2014), sedangkan penelitian ini didukung oleh (Ayuningtyas, 2012). Demikian kami simpulkan, lama tidaknya seorang auditor bekerja, banyak tidaknya tugas, maupun besar tidaknya perusahaan diaudit tidak menentukan kualitas audit yang dihasilkan dikarenakan masih ada orang yang memiliki bakat jenius dalam bidangnya dan sebaliknya juga ada orang yang sudah lama bekerja dibidang 
namun masih sering membuat kesalahan. Maka Pengalaman Kerja tidak berdampak terhadap Kualitas Audit.

\section{Pengaruh Fee Audit terhadap Kualitas Audit}

Fee Audit memiliki significance value sebanyak 0,377 > 0,05 dan thitung < ttabel $(3,639>2)$, maka Ha diterima dan H0 ditolak. Hasil ini didukung (Pramaswardana \& Ida, 2017) yang menemukan bahwasannya Fee Audit berdampak positif terhadap Kualitas Audit. Demikian kami simpulkan, dengan diberikannya fee tinggi, dapat memicu semangat auditor untuk menghasilkan audit yang berkualitas. Semakin sulit maupun kompleks audit yang dilakukan, semakin besar KAP yang dapat menaungi auditor dengan biaya yang tinggi mengartikan bahwa auditor tersebut dinilai ahli dalam menghasilkan kualitas audit yang bagus pula. Maka Fee Audit berdampak terhadap Kualitas Audit.

Pengaruh Professionalism, Etika Auditor, Pengalaman Kerja dan Fee Audit terhadap Kualitas Audit Didalam hasil uji hipotesis, variable bebas memiliki significant value 0,005 dibawah nilai 0,05 dan Fhitung > Ftabel $(4,239>2,76)$, maka H0 ditolak dan Ha diterima, yang berarti variable Professionalism, auditor ethics, Pengalaman Kerja, dan Fee Audit secara simultan berdampak significant terhadap Kualitas Audit. Demikian kami simpulkan, dengan memiliki sikap professional yang lebih baik, mempelajari etika audit, pengalaman dibidang auditor, dan biaya yang sesuai secara sekaligus dikuasai bisa menghasilkan kualitas audit yang lebih tinggi karena auditor tersebut sudah memiliki nilai yang jauh lebih tinggi, dan dapat memutuskan dalam pengauditan yang dilakukannya dengan sangat baik.

\section{Simpulan dan saran}

Kesimpulan penelitian menyatakan hasil pengujian secara parsial mempertunjukkan bahwasannya professionalisme dan pengalaman kerja tidak berdampak, etika auditor berdampak negatif, dan fee audit berdampak positif serta professionalisme, etika auditor, pengalaman kerja, dan fee audit berdampak atas kualitas audit pada Kantor Akuntan Publik Medan. Penentu professional atau tidaknya auditor tak ditentukan dalam menghasilkan kualitas audit, tak hanya dinilai dari laporan keuangan yang dihasilkan, juga kedekatan rekan professional, dan dedikasi terhadap pekerjaan mereka untuk peroleh indicator audit berkualitas tinggi. Semakin tingginya etika seorang auditor tidak dapat menjadi tolak ukur dalam menentukan hasil dari kualitas yang diauditnya, etika auditor adalah sikap dan perilaku dalam mentaati peraturan, kewajiban dan norma-norma dalam kehidupan, tidak dapat menentukan cermat atau telitinya seseorang dalam mengaudit laporan keuangan. Kemudian, lama tidaknya seorang auditor bekerja, banyak tidaknya tugas, maupun besar tidaknya perusahaan diaudit tidak menentukan kualitas audit yang dihasilkan dikarenakan masih ada orang yang memiliki bakat jenius dalam bidangnya dan sebaliknya juga ada orang yang sudah lama bekerja dibidang namun masih sering membuat kesalahan. Dan dengan diberikannya fee tinggi, dapat memicu semangat auditor untuk menghasilkan audit yang berkualitas. Semakin sulit maupun kompleks audit yang dilakukan, semakin besar KAP yang dapat menaungi auditor dengan biaya yang tinggi mengartikan bahwa auditor tersebut dinilai ahli dalam menghasilkan kualitas audit yang bagus pula. Meskipun pada hasil variabel individu yang diperoleh memiliki nilai yang berbedabeda, pada akhirnya dengan memiliki sikap professional yang lebih baik, mempelajari etika audit, pengalaman dibidang auditor, dan biaya yang sesuai secara sekaligus dikuasai bisa menghasilkan kualitas audit yang lebih tinggi karena auditor tersebut sudah memiliki nilai yang jauh lebih tinggi, dan dapat memutuskan dalam pengauditan yang dilakukannya dengan sangat baik. Untuk auditor muda dapat masih memiliki kesempatan untuk segera mengembangkan kualitas diri untuk mendapatkan kepercayaan dari para klien.

Saran yang dapat diberikan bagi auditor adalah dimanapun pelanggan berada, auditor wajib terlatih serta kompeten. Perusahaan bisa membantu auditor muda serta berpengalaman berkembang sebagai professional serta membuat keputusan yang lebih baik, berharap Pembaca akan mendapat manfaat dari penelitian akademis di masa depan mengenai kualitas audit. Meskipun sudah tersebar banyak tipe penelitian ini yang mirip, namun masih banyak hasil yang bisa diperoleh dalam penelitian karena menyangkut pendapat dan pemahaman dari responden yang terlibat berbeda-beda pemikirannya. Maka kepada peneliti lain semoga mendapatkan kreativitas yang lebih baik untuk mengembangkan penelitiannya mendapatkan hasil yang jauh lebih baik lagi. 


\section{Daftar Rujukan}

Agoes, S. (2012). Auditing (Pemeriiksaan Akuntan) oleh Kantor Akuntan Publik Edisi ke 4. Jakarta : Lembaga Penerbit Fakultas Ekonomi Universitas Indonesia.

Agusti, R., \& Pertiwi, N. P. (2013). Pengaruh Kompetensi, Independensi dan Professionalism terhadap Kualitas Audit (Studi Empiris pada Kantor Akuntan Publik Se Sumatera). 21(September), 1-13.

Ayuningtyas, H. Y. (2012). Pengaruh Pengalaman Kerja, Independensi, Objektifitas, Integritas, dan Kompetensi Terhadap Kualitas Hasil Audit. Jurnal Tema, 1(2).

Futri, S., \& Juliarsa, G. (2014). Pengaruh Independensi, Professionalism, Taraf Pendidikan, Etika Profesi, Pengalaman, Dan Kepuasan Kerja Auditor Pada Kualitas Audit Kantor Akuntan Publik Di Bali. EJurnal Akuntansi, 7(2).

Hanjani, A. (2014). Pengaruh Etika Auditor, Pengalaman Auditor, Fee Audit, Dan Motivasi Auditor Terhadap Kualitas Audit (Studi Pada Auditor Kap Di Semarang). Diponegoro Journal of Accounting, $3(2), 111-119$.

Ismiyati. (2012). Pengaruh Pengetahuan Dan Pengalaman Audit Terhadap Kualitas Audit (Studi Empiris Pada Kantor Akuntan Publik Di Jakarta Dan Bekasi). Yogyakarta State University, 1(1).

Kasbudiyani, E., \& Mahsun, M. (2017). Pengaruh Independensi Dan Etika Auditor Terhadap Kualitas Audit (Studi Empiris Pada Kantor Akuntan Publik Di Yogyakarta). STIE Widya Wiwaha.

Kurnia, Khomsiyah, \& dan Sofie. (2014). Pengaruh Kompetensi, Independensi, Tekanan Waktu, Dan Etika Auditor Terhadap Kualitas Audit. Jurnal Akuntansi Trisakti, 1(2).

Kusuma, N. F. A. (2012). Pengaruh Professionalism Auditor, Etika Profesi Dan Pengalaman Auditor Terhadap Pertimbangan Taraf Materialitas. Kajian Pendidikan Akuntansi Indonesia, 1(3).

Pramaswardana, I. G. N. I., \& Ida, B. (2017). Pengaruh Audit Tenure, Audit Fee, Rotasi Auditor, Spesialsiasi Auditor, Dan Umur Publikasi Pada Kualitas Audit. E- Jurnal Akuntansi, 19(1).

Primadi, R. (2018). Pengaruh Tekanan Klien, Audit Tenure, Fee Audit dan Kompetensi Auditor Terhadap Kualitas Audit Dengan Etika Auditor Sebagai Variable Moderasi Pada Kantor Akuntan Publik (Kap) Di Medan. Repositori Institusi Universitas Sumatera Utara.

Savitri, P. D., \& Astika, I. P. (2017). Pengaruh Etika Pada Hubungan Antara Pengalaman, Time Budget Pressure, dan Kompensasi Pada Kualitas Aaudit (Studi Empiris Pada Auditor Kantor Akuntan Publik Di Bali). E-Jurnal Akuntansi Universitas Udayana, 6(2), 445-476.

Tandiontong, M. (2013). Pengaruh Faktor Komitmen Profesi Akuntan, Komitmen Organisasi Kantor Akuntan Publik Dan Kepuasan Kerja Auditor Terhadap Implementasi Audit Independen Atas Laporan Keuangan Survei Terhadap Akuntan Yang Bekerja Sebagai Auditor Pada Kap Di Indonesia. . . Jurnal Ilmu Manajemen Dan Bisnis, 4(1).

Tandiontong, M. (2016). Kualitas Audit dan Pengukurannya. Bandung: Alfabeta. 